\title{
Biomaterials in 3D Printing: A Special Emphasis on Nanocellulose
}

\author{
Ravindra Vijay Badhe*, Anagha Godse, Ankita Ahinkar \\ Department of Pharmaceutical Quality Assurance, Dr. D.Y. Patil Institute of Pharmaceutical Sciences and Research, \\ Pimpri, Pune, Maharashtra, INDIA.
}

\begin{abstract}
Aim and Background: The main objective of this review is to highlight nanocellulosic materials in 3D bioprinting. Three-dimensional (3D) bioprinting is on the verge of fabricating the artificial organ and living tissues. For the target construction the process of this 3D bioprinting involves layer-by-layer deposition of suitable biomaterials using predesigned data made by using Computer Aided Design (CAD) as an outline. However, only a handful of biomaterials are able to fulfil the considerable requirements for suitable bioink formulation, which is a critical component of efficient 3D bioprinting. Conclusion: Cellulose, a naturally occurring polysaccharide, is clearly the most commonly employed material in current bioinks. Here, in this review we discuss the advantages, reasons, applications, disadvantages of the use of cellulosic bioink in 3D bioprinting by summarizing the most recent studies that used cellulose for printing vascular tissue, bone and cartilage. In addition, other breakthroughs in the use of cellulose in bioprinting are discussed, including strategies to improve its structural and degradation characteristics. In this review, we organize the available literature in order to inspire and accelerate novel cellulose-based bioink formulations with enhanced properties for future applications in basic research, drug screening and regenerative medicine.
\end{abstract}

Key words: Cellulose, Bioprinting, Regenerative medicine, Biomaterials, Bioink.

\section{INTRODUCTION}

The main objective of $3 \mathrm{D}$ bioprinting is to harmonizing live cells and permitting formation of 3D structure using predesigned CAD (computer aided design) software. Being a novel and progressive technology of science, it allows computerized programs and mimeographic production of artificial organ and tissues by layer-by-layer deposition of biomaterials along with suitable biochemicals with highly précised arrangement of cells. The technique of $3 \mathrm{D}$ bioprinting offers the advantages of formation of 3D structure, with wellarranged geometries, good reproducibility which is difficult to obtain by using $2 \mathrm{D}$ cell cultures and standard 3D cell cultures. The applications of such artificially formed 3D organs/tissues with live cells includes, basic investigation to study interaction of live cells and biomaterials at nanometres or micron level (before transplanting in animals), To tackle morphological deformities of tissues and obstruction in the functioning of organs using 3D bioprinting. ${ }^{1-3}$ We can use three fundamental approaches which includes extrusion, inkjet and laser assisted bioprinting (Figure 1).

Extrusion based bioprinters requires highly viscous bioink with shear-thinning property so that it can compensate with the high shear stress during printing. Extrusion based bioink, manifests printing of cell-laden constructs and maintains 3D construct controlled under required in physiological conditions. The bioprinters allows the discharge of bioink out of the nozzle by applying required mechanical force. Extrusion based bioprinters has relatively low cost, easy to operate, benefits of scalability; but it has comparatively less
Submission Date: 07-08-2019; Revision Date: 22-02-2020; Accepted Date: 19-05-2020

DOI: 10.5530/ijper.54.3.101 Correspondence: Dr. Ravindra Vijay Badhe Associate Professor, Department of Pharmaceutical Chemistry, Dr. D. Y. Patil Institute of Pharmaceutical Sciences and Research, Pimpri, Pune411018 ,

Maharashtra, INDIA.

Phone: +91-9422432038

E-mail: ravindra.badhe@ dypvp.edu.in

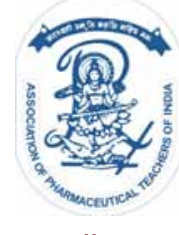

www.ijper.org 
resolution. Extrusion bioprinters also facilitates the formation of heterogeneous structures, because multiple cartridges can be loaded at a time. In this technique, the parameters like printing speed, pneumatic force and movement distance are critical for efficient printing., ${ }^{4,5}$ Inkjet based bioprinters are most widely used for cell-laden droplets at usually higher resolution. Inkjet bioprinters shows good viability than the extrusion based bioprinters. This inkjet bioprinters are driven either by heater or a piezoelectric transducer, which results in formation of air-bubble that further enlarges and allows the discharge of liquid out of the nozzle. This bioprinters offers advantages like, cost-effective, high resolution printing with high speed, highthroughput capability, reproducibility and ease of use. However, it has major disadvantage of nozzle clogging. This technique allows deposition of multiple cells/ proteins in very small droplets. In situation of inkjet bioprinting, low viscous solutions like suspension of cell or colloids are placed as a droplets using high shear rates (approximately $50 \mu \mathrm{m}$ in diameter) ${ }^{6-8}$

Laser assisted bioprinters uses a pulsed laser source, an absorption layer and a substrate for direct disposition of multiple cells and biological components on an arbitrary surface using laser beams for printing living tissues or organs. Before exposure of laser beam onto the printing surface, the absorption layer which is transparent to laser radiation is coated with biological materials which encapsulate the living cells and proteins. A focused laser beam is exposed on the absorption layer and it transfers heat, allowing the cell suspension to eject towards the substrate. The absorption layer prevents the direct interaction of laser beam and biological materials. This technique has an ability of printing small volumes of cell suspensions by high resolution. However, this technique is more expensive than previous two with limited scalability. ${ }^{9-11}$

Due to increasing complications in formation or fabrication of 3D network, researchers are facing difficulties in bioprinting process. The important aspect choosing biomaterial for bioink includes, compatibility with selected bioprinter to get uniform and effective printing. From this perspective, properties of bioink like, viscosity and non-newtonian behaviour play very important role towards maintaining viability of cells during bioprinting. Due to these reasons, hydrogel showing biomimicking nature with extracellular matrix and holding more than $90 \%$ of water content are considered as best bioink. In order to maintain, required mechanical properties of bioink and to eliminate the chances of destruction of 3D structure due to its low viscosity, the bioink is modified by complexing different polymers, forming composites of biomaterials or simply by incorporating nanoparticles into 3D network. ${ }^{12-14}$

For example, currently used bioink includes combination of both natural and synthetic biomaterials like, cellulosic nanofibrils with crosslinkable xylan. One of the study described, alginate and cellulose nanocrystals for bioprinting of liver. Mitogenic hydrogel system was developed by using cellulose nanofibres along with alginate sulphate. ${ }^{15-17}$ Thus, this review initially emphasizes on emerging field of 3D bioprinting along with its future perspective, advancements in formulation and development of cellulosic bioink as a novel, imminent field of biomaterials research.

\section{Properties of Bioink}

During the formulation/development and selection of bioink following parameters are needed to be considered and the comparative account of these parameters are mentioned in Table 1.

Bioprintability: The bioprintability of bioink varies with various factors like, Viscosity of bioink, Surface tension of bioink, Properties of printing nozzle, Crosslinking ability of solution, Efficiency of printing. The desired shape fidelity will be defined by the final bioprinting application and this can be improved by increasing the viscosity and final mechanical properties of a bioink. However, this can be achieved by increasing the concentration of the biomaterial or increasing the extent of cross-linking, both of these may affect cell viability. When biocompatibility is concerned, it is best to develop a bioink using a known biocompatible biomaterial which may then be optimized for printability. ${ }^{18,19}$

Biocompatibility with Live Cells: In human body, cells are present in an extracellular matrix (ECM), that has complex 3D structure, the cells inside ECM adapt their surrounding environment, by prompting physical and chemical functions, as it affects cellular functions. Although, ECM of each tissue has different composition due to different cellular components, it is basically composed of water, proteins and polysaccharide. Thus, materials used for $3 \mathrm{D}$ bioprinting must be biocompatible with cells seeded inside it and should mimic similar biological response to facilitate tissue formation/ organ formation and helps in cells adhesion and proliferation. The choice of cell source also decides the success of the $3 \mathrm{D}$ printed construct. Like, Stem cells have the ability to differentiate into multiple cell types and can build different tissues. Hence, Biomaterials necessity put up the encapsulated cells from the receiver's body, essentially be cytocompatible and support cell growth, attachment, proliferation and migration as well as it 
should not reason severe inflammation, immunologic rejection or genotoxicity. ${ }^{20-22}$

Viscosity: In an perfect complaint, viscosity of bioink should be supportive for specific cell type and should be suitable for printing; But, viscosity of cell supporting bioinks and viscosity of printable bioinks are different so as to support live cells. Thus, either cells incorporated in bioink has to undergo stress or printability has to be compromised. Many studies has been carried out, to improve printability of bioink viscosity of cell-supportive viscosity of bioink mainly, by varying printing parameters or changing strategies of printing. ${ }^{23,24}$ Thus, optimization of bioink consistency and printing conditions are required to attain high cell viability and printability.

Shear thinning behaviour/viscoelasticity: For 3D bioprinting, both non-newtonian and Newtonian bioinks are used. Viscosity of non-newtonian bioinks can be resolute by, Amount of strain rate during printing, Concentration of bioink, Molecular weight. Additionally, in case of temperature sensitive bioink nozzle shape, size and temperature also affects the strain rate during printing. In case of shear thinning bioinks, viscosity decreases with increased strain rate, it helps in protecting cells incorporated and improving resolution. Shear thinning bioinks, due to limited entanglement of chains, facilitates efficient extrusion of bioink through printing nozzle, this is due to sliding of chains over one another. Various bioinks are formulated for various purposes and each bioink distinctly affected by shear force applied during printing. Shear force especially affects, when the bioink is present near walls of syringe/needles. Shear force applied during printing is experienced by cells encapsulated in bioink and it is majorly affected by, Dispensing pressure, Concentration of biomaterial in bioink, Diameter of nozzle. The applied shear stress in turn affects viability of cells. Shear stress is inversely proportional to nozzle diameter and cell viability. But, it is directly proportional to resolution. Another major problem is, concentration of bioink affects cell viability. It is seen that, in case of majority of bioinks increased concentration, decreases cell viability (majorly observed in alginate and gelation based bioink). This is generally due to, high concentration of biomaterial in bioink prevents migration of cells and also prevents diffusion of nutrients due to entangled network, which ultimately results in decreased in cell viability. ${ }^{25-28}$

Biodegradation: The degradability of bioink materials is another important factor during selection of bioink in 3D printing, an ideal bioink should be able to degrade in-vivo with time and at a controlled rate. Bioink is expected to create similar biological environment for growth of engineered tissue and the degraded products must be non-toxic to cells incorporated inside tissue. Depending upon the type of biomaterials used, concentrations, temperature, situations (in vitro or in vivo) and existence of external additives the degradation of bioink varies. Degradation can be diverse by hydrolytic or enzymatic labile components within a bioink. Additionally, the presence of cells within 3D constructs limits the choice of formulation components, still maintains mechanical strength. Because of incorporation of hard polymer in bioink, it is observed that microcarriers degrade slower than hydrogels and can release substances that are noxious to cells. ${ }^{29-31}$

Permeation of oxygen and nutrients: The bioink should be able to permeate oxygen and nutrients in sufficient amount for optimal development and survival of engineered tissue. In case of tissue with clinically relevant size, the mass transport of nutrients and oxygen is often insufficient to sustain all cells incorporated in tissue. In some of the cases, it is observed that, after

\begin{tabular}{|c|c|c|c|c|c|c|}
\hline \multicolumn{7}{|c|}{ Table 1: Comparison of Parameters. } \\
\hline Parameter & Hydrogels & $\begin{array}{c}\text { Decellularized } \\
\text { matrix }\end{array}$ & Microcarriers & $\begin{array}{c}\text { Tissue } \\
\text { spheroids }\end{array}$ & Cell pellet & $\begin{array}{c}\text { Tissue } \\
\text { strands }\end{array}$ \\
\hline Resolution & High & Medium & Low & Low & Medium & Low \\
\hline Accuracy & High & Medium & Low & Low & Medium & Low \\
\hline Bioprinting time & Short & Medium-long & Short & Long & Medium-long & Long \\
\hline Cell viability & High & Medium-high & High & Medium-high & Medium-high & Medium-high \\
\hline Bioprintability & High & Low-medium & High & Low & Low-medium & Low \\
\hline Bioink viscosity & low to high & Medium to high & NA & NA & Medium to high & NA \\
\hline $\begin{array}{c}\text { Cell } \\
\text { interactions }\end{array}$ & Low & High & Medium & High & High & High \\
\hline $\begin{array}{c}\text { Tissue } \\
\text { biomimicry }\end{array}$ & $\begin{array}{c}\text { Low- } \\
\text { medium }\end{array}$ & Medium-high & Medium & High & Medium-high & High \\
\hline
\end{tabular}


implementation of engineered tissue inside body, the vascular construct is not readily established and mass transport of nutrients becomes challenging. Thus, to resolve such problems bioink which allows transport of oxygen and nutrients are more selective.

In situ gelation: Bioinks expected to have an in-situ gelation property, as such systems forms sol before entering into body, but changes to gel under physiological conditions. The in-situ gelation of bioink protects the cells from environmental conditions. Such bioinks can also be engineered to exhibit bioadhesiveness to facilitate targeted cell growth. Bioink with synthetic polymers allows modification in degradability and functionality. ${ }^{32-34}$

Cell viability and proliferation: Cell viability in bioink is affected by the type of bioink, its concentration, post encapsulation time. Some of reported studies linked cell viability in several bioink. One of the study, linked the effects of Matrigel, Pluronic ${ }^{\circledR}$ F-127 (25\%), alginate $(2 \%)$ and agarose $(1 \%)$ on cell practicality over time. It was observed that after incubating for five hours there no significant change in cell viability were observed; after one day, the cell viability in Pluronic ${ }^{\circledR}$ reduced to $20 \%$. After seven days, cells in Matrigel and alginate showed $90 \%$ viability, while viability in agarose reduced to $70 \%$ and no viable cells were observed in Pluronic ${ }^{\circledR}$. In the same study, no significant change in $3 \mathrm{D}$ printed and manually placed scaffolds in terms of cell viability and proliferation. Concentration of bioink also affects cell viability, i.e. blend of $5 \%$ gelatin and $1 \%$ alginate preserved nearly $100 \%$ viability; though, in a blend of $10 \%$ gelatin and $1 \%$ alginate, the viability reduces to $70 \%$ after six hours post bioprinting. A $2 \%$ alginate concentration sustains about $90 \%$ viability, whereas $6 \%$ outcomes in only $35 \%$ viability. ${ }^{35-37}$

Biomimicry: 3D bioprinting aims to regenerate the tissues and organ. It is achieved by regenerating specific functional cellular component of tissues or organs. For example, by mimicking ECM of different organs or tissues using physiologically similar biomaterials and gradients. But, the successful regeneration of organs requires proper understanding of microenvironment that is specific hierarchical arrangement of functional and supporting cells. It also includes, overall composition of ECM, soluble and insoluble gradient. ${ }^{38}$ Cell encapsulation in bioinks permits modeling of cells; though, subsequent ECM formation, digestion and degradation of the hydrogel matrix, interactions and proliferation of encapsulated cells are all matters that need cautious consideration. Thus, knowledge regarding biomimicking nature of bioink is required for successful development of functional organs and tissues.
Resolution: Resolution of 3D bioprinting affected by the modality of bioink and the bioink. During bioprinting of cells using laser based bioprinting (LBB), $5.6 \pm 2.5 \mu \mathrm{m}$ resolution can be obtained. But comparatively, in extrusion based bioink (EBB) and droplet based bioink (DBB), the better resolution can be obtained to approximately 100 and $50 \mu \mathrm{m}$, respectively. Encapsulating cell aggregates and microcarriers during EBB can further reduce the resolution. Specifically, cell encapsulated in spheroid and strand methods has a diameter ranging from 250 to $450 \mu \mathrm{m} .{ }^{39,40}$ Even though bioprinting of a cell pellet shows higher resolution when compared to resolution of tissue spheroids and strands, a reduced nozzle diameter it reduces the resolution of cell pellet this is because cells are directly exposed to the shear stress. Although organ can be designed by using original size and shape, structure can be closely made-up by means of such bioink materials, most of them do not retain shape and may feast, shrink or swell dependent on the bioink and culturing situations.

Practicality: Biomaterials-based bioink materials is considered as the most practical bioink type for bioprinting tissues and organ; the process offers ease of bioprinting by simply loading cells in 3D matrix. Different bioink possess different levels of ease in bioprinting, which depends on the crosslinking mechanisms. On the other hand, preparation and processing of synthetic bioink is quite challenging. For example, formulation of bioink with cell aggregates is expensive and time consuming. The addition of bioink in the bioprinting process is an important requirement for an extrusion process. But, supporting aggregation of cells and fusion of cell aggregates makes the whole process bit difficult. For preparation of ECM, the bioink with suitable biological and biochemical properties is needed. Furthermore, addition of cells into compatible bioink increases complexity in the process. In case of microcarriers, primary need is to fabricate the porous biodegradable delivery that allows initial cell seeding. Once thecells are seeded into microcarriers, microcarriers are further loaded into bioink for the mission of bioprinting. Thus, considering practicality during processing is an important factor, as not all types of bioink supports cells seeding and proliferation, it requires multi-step approach, which is does not offers ease of practicality. ${ }^{41,42}$

\section{Bioprinting and post bioprinting incubation time:}

The bioprinting period varies with type of organ/ tissue, its size, porosity and resolution of bioink. In general, the bioprinting period of bioink and microcarriers loaded on bioink is comparatively less (i.e., few minutes). While, bioprinting of $\mathrm{dECM}$ is more, this is due to time 
required for solidification of outer ECM. Bioprinting of cell aggregates like tissue spheroids requires pickand-place type of robotic arm as a dispenser and time required for printing may vary as per size and complexity of an organ. (i.e. minutes to an hour). Additionally, printing of supporting mold needs extended fabrication times. Although the bioprinting time is longer for cell aggregates, post-printing maturation and tissue formation time is relatively less as compared too bioink and microcarrier loaded bioinks. ${ }^{43}$ Different strategies to improve these parameters are mentioned in Table 2.

Biomaterials for Bioink: The biomaterials used for preparation of bioink should enable better cell attachment, growth and proliferation inside artificial $3 \mathrm{D}$ construct. It should have convenient modifiable functional groups and should deliver different signals/ biomimicking behaviour and molecules. There are two types of biomaterials used during formulation of bioink including, Natural and Synthetic biomaterials. Natural biomaterials plays integral role in constructing extracellular matrix as a substrate for cells. Natural biomaterials can be derived from plants and animals origin. Preferably, animal origin biomaterials are used for formulations of bioink, as it facilitate comparatively better cell growth and function. Synthetic bioink offers the advantages of controlled mechanical properties, good biocompatibility cross-linking. ${ }^{44}$ Both of these biopolymers has its own advantages and disadvantages. The Figure 2 shows different biopolymers for 3D bioprinting.

Collagen: Being a vital component of ECM and biocompatible natural biomaterial, collagen is a top ranked biomaterial in 3D Printing. Collagen can be used alone or in combination, to increase its performance and selectivity as a bioink. In the literature review, it has been observed that collagen when cross-linked by using specific temperature, changing $\mathrm{pH}$ and crosslinking with vitamins like riboflavin, it shows increased tensile strength and better shear-thinning properties, when compared with non crosslinked collagen. However, during crosslinking and gelation of collagen, temperature is maintained to $37^{\circ} \mathrm{C}$ for about $30 \mathrm{~min} .{ }^{45}$

\section{Examples of collagen based bioink}

- Collagen with sodium alginate used in development of 3D construct of chondrocytes. In this study, Yang et al. demonstrated the better cell attachment and proliferation. ${ }^{46}$

- In other study, collagen-gelatin used to develop $3 \mathrm{D}$ construct by using drop-on-demand method to study the co-culture of human endothelial cells and hMNCs. ${ }^{47}$
Alginate: Natural biopolymer derived from brown algae, which is inexpensive and popularly known as alginic acid. It is negatively charged polysaccharide, which do not exhibit any inflammatory response, when implemented in-vivo. It has repeating units of monomers like, $\alpha$-L-guluronic acid and (1-4)- $\beta$-Dmannuronic acid. Each of this monomer has its own characteristics $\alpha$-L-guluronic acid helps in gel formation and (1-4)- $\beta$-D-mannuronic acid helps in increasing flexibility of materials. The alginate biopolymers using capillary forces can entrap water and other molecules, allowing it to diffuse inside out. ${ }^{48}$

\section{Examples of alginate based bioink}

- Alginate-based bioinks are used to print hollow construct with cartilage cells. In this study, Zhang et al. demonstrated that these vessels like printable microfluidic channels are capable of transporting nutrients and oxygen. ${ }^{49}$

- In another study, Gao et al. reported a co-axial system in which, Micro-channelled 3D construct of high strength for nutrient delivery was printed using alginate-based hydrogel. ${ }^{50}$

Agarose: Agarose is aquatic polysaccharide, derived from seaweed. It has wide applications, in biomedical field as it has gel forming property. Agarose is a linear polysaccharide chain containing, agarbinose repeating unit. One repeating unit of agarbinose, consist of disaccharides, D-galactose and 3-6 anhydroL-galactopyranose. Agarose has good mechanical properties, biocompatibility and gelation properties, but has limited cell growth. After extensive literature review, it was observed that, even though agarose has good gelling properties; chemical modifications and blending with other biopolymer makes it more selective as a bioink and also enhances cellular functions. ${ }^{51}$ Thus, researchers recommends that instead of using agarose alone, it's better to use it in conjunction with other biopolymer.

\section{Examples of agarose based bioink}

- Kreimendahl et al. reported the blend of agarosecollagen and fibrinogen which was used to form stable 3D construct that supported growth of fibroblast and endothelial cells. ${ }^{52}$

- $\mathrm{Gu}$ et al. used agarose-alginate and successfully printed 3D construct with induced pluripotent stem cells for developing functional neurons. ${ }^{53}$

Silk Based Bioink: Silk is high molecular weight natural protein derived from silk-worm and spiders. This silk based bioink has frequent applications in regenerative medicines and tissue engineering. Due to its exceptional 
properties, like non-toxic nature, slow degradation, less immunogenicity, good viscoelastic properties, increased viscosity and its ability to form $\beta$ sheet structure during gelation, it provides good mechanical properties.
Although, silk has various advantages using pure silk as a bioink causes the problem of nozzle clogging, due to its high viscosity. The shear forces inside nozzle, causes the formation of $\beta$-crystallites because of presence of

\begin{tabular}{|c|c|c|c|c|}
\hline $\begin{array}{l}\text { Sr. } \\
\text { No }\end{array}$ & Objective & Approaches & Advantages & Disadvantages \\
\hline \multirow{7}{*}{1} & \multirow{7}{*}{$\begin{array}{l}\text { To enhance } \\
\text { printability of } \\
\text { bioink }\end{array}$} & $\begin{array}{l}\text { Blending with other } \\
\text { biopolymers }\end{array}$ & Enhances the viscosity of bioink & Reduce cell viability \\
\hline & & Co-axial nozzle & $\begin{array}{c}\text { Improves resolution, Allows fabrication of } \\
\text { heterogeneous construct, Multimaterial } \\
\text { deposition }\end{array}$ & $\begin{array}{l}\text { Low cell viability during } \\
\text { printing }\end{array}$ \\
\hline & & $\begin{array}{l}\text { Crosslinking using } \\
\text { synthetic polymers }\end{array}$ & Improves viscosity and resolution & $\begin{array}{l}\text { Lowers overall mechanical } \\
\text { properties and reduces cell } \\
\text { viability }\end{array}$ \\
\hline & & $\begin{array}{l}\text { Cell loaded micro-carriers } \\
\text { laden bioink }\end{array}$ & $\begin{array}{l}\text { Improves mechanical strength, } \\
\text { Allows the priting of low viscosity bioink, } \\
\text { Enables fabrication of heterogeneous construct }\end{array}$ & Limited resolution \\
\hline & & $\begin{array}{l}\text { Cell spheroids laden } \\
\text { bioink }\end{array}$ & $\begin{array}{l}\text { Controls the dimensions of 3D construct, } \\
\text { Reduce shear stress during printing }\end{array}$ & $\begin{array}{l}\text { Large constructs cannot be } \\
\text { constructed }\end{array}$ \\
\hline & & $\begin{array}{l}\text { Interpenetrating } \\
\text { hydrogels }\end{array}$ & Enhances the viscosity of bioink & Reduce cell viability \\
\hline & & $\begin{array}{l}\text { Nanoparticles loaded } \\
\text { bioink }\end{array}$ & $\begin{array}{c}\text { Enhances viscosity with shear thinning } \\
\text { properties, Better resolution, Protecting cells } \\
\text { from printing stress }\end{array}$ & $\begin{array}{l}\text { Low cell viability after } \\
\text { bioprinting }\end{array}$ \\
\hline \multirow{8}{*}{2} & \multirow{8}{*}{$\begin{array}{l}\text { To improve shape } \\
\text { fidelity }\end{array}$} & $\begin{array}{l}\text { Modifying self assembled } \\
\text { moieties }\end{array}$ & Safe-guards of cells from printing stress & $\begin{array}{l}\text { Difficult to control properties } \\
\text { of self assembled bioink }\end{array}$ \\
\hline & & $\begin{array}{l}\text { Photo-chemical } \\
\text { crosslinking }\end{array}$ & Increases mechanical strength & Reduces cell viability \\
\hline & & Ionic crosslinking & Increases mechanical strength & $\begin{array}{l}\text { Reduces cell viability, } \\
\text { Inefficient for multilayered } \\
\text { construct }\end{array}$ \\
\hline & & $\begin{array}{l}\text { Optimization to quantify } \\
\text { shear stress during } \\
\text { bioprinting }\end{array}$ & $\begin{array}{l}\text { Improves cells viability, Improves printing } \\
\text { resolution }\end{array}$ & $\begin{array}{l}\text { Optimization is limited to } \\
\text { few bioink and are not } \\
\text { applicable for other bioinks }\end{array}$ \\
\hline & & $\begin{array}{l}\text { Concomitantly printed } \\
\text { scaffolds }\end{array}$ & $\begin{array}{c}\text { Improves mechanical strength and efficient } \\
\text { diffusivity of construct }\end{array}$ & Involve synthetic bioink \\
\hline & & Sacrificial scaffolds & $\begin{array}{l}\text { Allows the printing of complex shapes, } \\
\text { Efficient diffusion characteristics }\end{array}$ & $\begin{array}{l}\text { Toxicity in case of synthetic } \\
\text { scaffolds }\end{array}$ \\
\hline & & $\begin{array}{l}\text { Crosslinking with } \\
\text { supportive scaffolds }\end{array}$ & Improved mechanical strength and stability & Rapid degradation \\
\hline & & $\begin{array}{l}\text { Bioink for non-porous } \\
\text { scaffolds }\end{array}$ & $\begin{array}{l}\text { Improves diffusion of nutrients, Maintains shape } \\
\text { fidelity }\end{array}$ & Toxic synthetic polymers \\
\hline \multirow{5}{*}{3} & \multirow{5}{*}{$\begin{array}{l}\text { To acquire good } \\
\text { cell viability and } \\
\text { function }\end{array}$} & $\begin{array}{l}\text { RGD modification of } \\
\text { sequence of amino } \\
\text { acids (Arginine-Glycine- } \\
\text { Aspartic acid) }\end{array}$ & Improves cell adhesion and viability & - \\
\hline & & $\begin{array}{l}\text { Blending with } \\
\text { biopolymers containing } \\
\text { cell binding domains }\end{array}$ & Improves cell binding and viability & Reduces printability \\
\hline & & $\begin{array}{l}\text { Decellularized ECM } \\
\text { (ECM without cells) }\end{array}$ & Provide native microenvironment to laden cells & $\begin{array}{l}\text { Reduces viscosity and } \\
\text { resolution }\end{array}$ \\
\hline & & Printing temperature & Improves cell viability during bioprinting & Reduces printability \\
\hline & & Vascularized constructs & Better diffusion which improves cell viability & - \\
\hline
\end{tabular}


polypeptide chains, which clogs the nozzle. Thus, to avoid this silk is used in different recombinant versions. ${ }^{54}$

\section{Examples of silk based bioink-}

- Das et al. reported, the use of silk-gelatin based bioink for 3D bioprinting of cell laden constructs using mesenchymal progenitor cells and crosslinking the silk-gelatin using sonication and enzymatic crosslinking. ${ }^{55}$

- Zheng et al. reported free standing 3D construct made from silk-PEG blend and proved that using high content of silk increases cell viability to a large extent. $^{56}$

Fibrin Based Bioink: Fibrin is a protein mostly found in blood and it helps in clotting, the hydrogel of fibrin can be synthesized by enzymatically treating thrombin from fibrinogen. It has excellent biocompatibility and biodegradation properties, but it shows very weak mechanical properties. Fibrinogen based bioink has less viscosity and, inkjet 3D bioprinters are used in this cases. When it is to be used in case of extrusion based bioink, fibrinogen need to be added with other biopolymer to improve bioactivity and mechanical strength after crosslinking. Fibrin based gel is formed by cross-linking fibrinogen with thrombin and incubating it at room temperature. ${ }^{57}$ Thrombin cleaves the fibrinogen and results in formation of two symmetrical structures, which later aggregates non-covalently.

\section{Examples of fibrin based bioink}

- England et al. reported, the fibrin-HA based hydrogel for encapsulating Schwann cells which are used for 3D printing of nerve conduit (tube like structure). ${ }^{58}$

- Zhang et al. reported, that fibrin hydrogels along with polycaprolactone can be used to develop 3D construct of urethra and seeded with multiple cells to check effect of this material..$^{59}$

Hyluronic Acid Based Bioink: Hyluronic acid is a glucosaminoglycan biopolymer with disaccharide unit of $\mathrm{N}$-acetyl-D-glucosamine and $\mathrm{D}$-glucuronic acid. It is a natural component of extracellular matrix mostly seen in connective tissues and cartilages. Inside tissues it plays important roles like, structural integrity, hydration to ECM, influences cell growth, proliferation and migration, tissue homeostasis. Hyluronic acid being a prominent biomaterial is used for developing different 3D construct. Hyluronic acid has high viscosity, due to its high viscosity, used as a supportive hydrogel for modifying the viscosity of bioink. The viscosity of hyluronic acid based bioink is depends on concentration. ${ }^{60}$ Although, hyluronic acid has high viscosity it has poor mechanical strength, it can be resolved by crosslinking.

\section{Examples of hyluronic acid based bioink}

- Poldervaart et al. recently reported, the 3D bioprinting of HA-based hydrogels, which is chemically modified by using methacrylate and showed high osteogenic properties. ${ }^{61}$

- Sakai et al. reported, the HA- gelatin based bioinks polymerized by using visible light with the help of ruthenium based complexes and proved enhanced cell viability and differentiation of human stem cells. $^{62}$

Synthetic Biopolymer Based Bioink- Even though, natural biopolymers provides required environment mimicking native ECM for attachment of cell and proliferation of cell, the tunable properties of the polymers are limited. Hence, combining this natural polymer, with synthetic polymers offers the advantages of both of these biopolymers and helps in forming stable 3D construct. The blend of natural-synthetic biopolymer offers both the advantages like enhanced cellular adhesion improving mechanical properties, printability and crosslinking. ${ }^{63}$ The most widely used synthetic biomaterials include, PEG based bioink and Pluronic acid based bioink.

\section{Examples of synthetic biopolymer based bioink-}

- Wu et al. reported, the printed microchannel using pluronic acid in photo-polymerizable polymer and developed microvascular structures. ${ }^{64}$

- Mozetic et al. reported, the blend of pluronic acid and alginate to investigate its effect of myoblast cells viability and alignment. ${ }^{65}$

- Muller et al. Reported, the development of more stable UV cross-linked 3D construct using acrylated pluronic acid. ${ }^{66}$

- Peppas and his team reported, polyethylene glycol based bioink as a drug delivery system for controlled release. ${ }^{67}$

Cellulose Based Bioink: Cellulose is a carbohydrate polymer that contains long chains of $\beta-(1,4)$ linked D-anhydroglucopyranose moiety. In cellulose based bioink, most widely used semi-flexible carboxy methyl cellulose is used. Carboxymethyl cellulose, by changing its concentration, molecular weight and degree of methylation can be converted to environment sensitive hydrogel. In the formulation of cellulosic bioink, pretreated cellulosic nanofibrils/cellulosic nanocrystals are used. ${ }^{68}$ Cellulose is being used extensively in biomedical field, including tissue engineering andregenerative medicines. 


\section{Examples of cellulose based bioink}

- Markstedt et al. stated a cellulose nanofibrils and xylans based bioinks for 3D printing with high integrity and excellent printing properties. ${ }^{69}$

- Avila et al. Reported, nanocellulosic hydrogel which was used for evolving patient-specific auricular cartilage tissue from 3D printing. ${ }^{70}$

Cellulosic Bioinks: Cellulose is a lined carbohydrate biopolymer composed of $\beta$ (1-4) linked D-anhydropyranose repeating units derived from biosynthesis of plants orbacteria. The term nanocellulose mentions to processed cellulose / cellulosic extracts, that has one dimension in nanometer range. ${ }^{71}$ Cellulosic materials depending upon its source and method of preparation categorized into three groups like,

- Nanofibrillated cellulose

- Cellulosic nanocrystals

There are various reasons due to which the cellulose derivatives nowadays are being used as a bioink, in 3D bioprinting. These reasons are diagrammatically shown in Figure 3.

It is renewable, economical, widely and easily available, biodegradable, biocompatible, higher stiffness, insoluble in water and solvents. Apart from these basic reasons, there are some specific reasons like, it shows good rheological behaviour (shear thinning behaviour), its ability to support cell growth and cell proliferation, Shape fidelity after bioprinting and it accurately controls the pore structures which makes it a important choice for mechanically stable bioink for 3D bioprinting. ${ }^{72}$ The general procedure for formulation of bioink is shown in Figure 4. The pre-treatments for cellulose for nanocellulosic production is shown in Figure 5.

Cellulose Nanofibres (CNF): Cellulose nanofibre (nanofibrillated cellulose, microfibrillated cellulose, cellulose nanofibrils) can be extracted from crude cellulose obtained from wood, sugar beet, potato tuber, hemp, flax by combination of mechanical and chemical treatments. Cellulose nanofibrils, includes different regions of cellulose, by mechanical shearing which includes, grinding, high-pressure homogenization and forms the cellulose having diameter in nanoscale range and length in micron scale. The process of formation of cellulose is promoted by chemical pretreatments like, TEMPO oxidation, Acid hydrolysis, Enzymatic reactions. In case of removing lignin and hemicelluloses, from crude cellulose, the crude cellulose is subjected to enzymatic degradation in the presence of micro-organism, like fungi. Further, the nanofibrils are obtained by removing the bacterial content and growth medium. The morphology of cellulose is depends upon the applied culturing conditions. ${ }^{73}$ The resulting cellulose nanofibrils are comparatively long and entangled fibrils with both, amorphous and crystalline region. The nanofibrils of cellulose has the ability to form highly entangled gel network which has high viscosity, even when used in low concentration (1\%).

The isolation of CNFs from cellulose source materials divides in two stages. The first stage one is a purification step and second one is homogenization pre-treatment of the crude source material so that it reacts more effectively in subsequent treatments. The particular, pretreatment is dependent on the crude source of cellulose and to a lesser degree on the desired morphology of the starting cellulose material for the second stage treatments. Cellulose is present in wood or plants in combination with hemicellulose and lignin. The latter are removed before the production of CNF by various cooking and bleaching methods, which are similar to those used in papermaking industry. CNF production methods usually comprise several operations, like, successive refining, enzymatic hydrolysis, again refining and finally homogenization TEMPO-mediated oxidation, followed by blending or homogenization, carboxymethylation, or quaternization, followed by homogenization. Thus, the production process is a combination of different operations, by varying which different kinds on CNF are obtained. ${ }^{74}$ Various grades of CNF differ in morphology (particularly nanofibrils dimensions and the amount of residual microscopic fiber fragments), surface chemistry, crystallinity, etc.

The CNFs are generally obtained by mechanical disintegration of crude cellulose, Different crude sources of cellulose gives various features of CNFs and likewise dissimilar aspect ratios $(\mathrm{L} / \mathrm{d}$, where $\mathrm{L}$ is the length and $\mathrm{d}$ is the diameter). A representative aspect ratio for CNF after 15-100. CNFs are separated fibrils after the interfibrillare hydrogen bonds is broken due to dissimilar treatments; though, the fibrillar structure is consists of periodical pre-arrangement of crystalline and amorphous domains. Fibres are obtained with micrometre size in length and nano-metre size in width. When compared to $\mathrm{CNCs}$, CNFs has high aspect ratio and semi-crystalline structure exhibit unique property to form entangling networks, benefiting for the formation of more mechanically stable bioink by themselves. $\mathrm{CNF}$ s can be used as reinforcing agents (fillers) to form composite bioink which provides excellent mechanical property. However, the loadings of CNFs are less than that of $\mathrm{CNCs}$ due to the entanglement of $\mathrm{CNFs}^{75}$ Additionally, it has been reported that more flexible hydrogels/ bioink can be attained by combining CNFs 
due to their high aspect ratio and semi-crystalline structure.

The properties of aqueous solutions exhibits different properties based on different production process. Rheological property is one of the important parameters used to describe CNF suspensions. The manufacture approaches, like biological or chemical pre-treatments, does not affect rheological properties and all of them exhibits gel-like, shear thinning and thixotropic behavior at low concentration of solid content. Though, these suspensions can be further processed to other CNF products, for example, hydrogel /bioink for 3D printing. ${ }^{76}$ To obtain the nanofibers from plants and wood fibers, it is necessary to disrupt the fibers original structure.

The use of CNF in an industrial applications is limited due to several reasons. First and foremost, CNF have a high hydrophilic character, which has a ability to form in highly viscous aqueous suspensions even at low solid content. Second, cellulose undergoes through irreversible aggregation while drying. Thus, one of the challenges is to produce dry CNF powder that has a preserved nanoscale structure and this approach helps into ensuring its re-dispersibility. This approach can provide advantages in $\mathrm{CNF}$ storage, transportation and industrial applications. ${ }^{77}$ Thus, being a novel nanomaterial $\mathrm{CNF}$ has been widely investigated as potential materials for 3D Bioprinting, due to their biocompatibility, biodegradability and low cytotoxicity as well as tuneable chemical and physical properties, which is an ultimate need during selection of bioink.

Cellulosic nanocrystals (CNC): Cellulose nanocrystals are one of the novel biomaterials derived from the cellulose which is abundant and renewable natural biopolymer. CNC's have recently gained attention of researchers due to their acceptable chemical, optical, mechanical and rheological properties. These CNC's are obtained from cellulosic nanofibres derived from naturally abundant sources like plant, bacterial and tunicate. In order to isolate CNC's from cellulosic nanofibres, the CNF's are subjected to acid hydrolysis under controlled conditionc like temperature, time, Concentration (using 64\% sulfuric acid, at $70^{\circ} \mathrm{C}$ for $30 \mathrm{~min}$. In laboratory experiments, about $\sim 40 \%$ yield of CNC's drecreases. While isolating from plant celluloses as starting materials because it contains, the disarranged regions are detached during acid hydrolysis. ${ }^{78}$ Nanocrystals prepared from plant celluloses shows rod-like structures with average widths $\sim 15$ and length of $\sim 150 \mathrm{~nm}$, respectively. CNC's are decomposable and renewable in nature and henceforth they aid as a sustainable and environment friendly derivative for biomedical applications. These CNC's are essentially hydrophilic in nature; though, their surface can be modified to encounter various stimulating requirements, such as the advancements in the field of nanocomposites, by means of hydrophobic polymer. CNC's exhibits unique property that they form, chiralnematic ordered crystalline network in water with high solid contents, such networks are only observed in CNC's, not in CNF's. ${ }^{79}$

These CNC's are referred to as whiskers, micro crystallites, nonetheless the maximum widely acknowledged nomenclature is CNCs. Linked to bulk cellulose, CNC's has better amorphous parts, which show high specific strength, modulus, high surface area and exclusive liquid crystalline properties. The sizes of $\mathrm{CNCs}$, like length and width, varies dependent on the source of cellulose Nano fibres and controlled conditions of acid hydrolysis. The aspect ratio of $\mathrm{CNC}$ is from 1 to 100. CNC shows a moderately wide dispersal in length and width due to the diffusion-controlled nature of the hydrolysis process. The quantitative evaluation of strength and tensile modulus of CNC's along multiple axes is quite challenging. ${ }^{80}$ Additionally, factors like sizes of the samples, percentage crystallinity, anisotropy, defects in the nanocrystals affects the results. In case of calculating elastic properties of CNC's atomic force microscopy (AFM), Raman scattering, X-ray diffraction analysis, inelastic X-ray scattering, can be carried out.

Under controlled conditions and at critical concentrations, asymmetric rod-like or spindle-like particles immediately form ordered structures, leading to the formation of a nematic or cholesteric phase. These rod-like CNCs, when dispersed in water, selfalign themselves to form chiral nematic phases with liquid crystalline properties. Their aspect ratios, stiffness and the ability to align under certain conditions make them ideal for showing liquid crystalline behaviour. ${ }^{81}$ However, CNC's are reported to have a helical twist athe end of the long axis (similar to a screw) which can either form a chiral nematic or a cholesteric phase of stacked nanocrystals aligned along a perpendicular axis based on the concentration. Various factors like size, charge, shape, dispersity, electrolyte and external stimuli can also affect the liquid crystallinity of CNC.

Rheological properties of $\mathrm{CNC}$ are affected by properties like liquid crystallinity, ordering and gelation properties. Dilute $\mathrm{CNC}$ suspensions exhibits shear thinning behavior, which shows concentration dependant at low rates. When in higher concentrations, lyotropic suspensions are formed, they shows an anomalous behavior. The main reason for this behavior is that the rod-shaped nanocrystals aligns themselves at 
a critical shear rate. When the shear rate reaches a critical point, the chirality of the $\mathrm{CNC}$ suspension breaks down to form of a simple nematic structure. ${ }^{82}$ Additionally, the relaxation time constant depends on the aspect ratio and CNCs with higher aspect ratios remained aligned for longer times even after shear. The type of acid used for hydrolysis can also affects the rheological properties of $\mathrm{CNC}$ suspensions.

CNCs shows surface-to-volume ratios, in addition to hydroxyl groups, which makes it appropriate for various types of surface modifications. In using any chemical functionality on their surface, the kind of interactions that the material displays with its environments can be altered. Normally used surface modifications for CNCs includes esterification, nucleophilic substitution etherification, oxidation, amidation, carbamation, silylation, polymer grafting, etc. The key benefit of chemical alteration is that it can present either negative or positive electrostatic charges on the $\mathrm{CNC}$ surface, which ultimately provides improved diffusion in any solvent/polymeric solution. It also aids to compensate the superficial energy features to improve compatibility, particularly in case of nonpolar or hydrophobic polymer matrices. ${ }^{83}$

Thus, CNC is reported as a novel biomaterials with a wide variety of other nanostructured derivatives because of its advantages like its renewability, sustainability, nontoxic and biocompatibility nanomaterial. Owing to its nanorange dimensions, large aspect ratio and good mechanical and chemical properties, $\mathrm{CNC}$ also reported to have various applications in one or the other area, like tissue engineering and medicine. The upcoming industrial extraction method to get $\mathrm{CNC}$ in pilot quantities needs further optimization in order to get greater yield and quality. The Dispersion and distribution of $\mathrm{CNC}$ in a polymer matrix is still a critical issue, this is due to difficulty in attainment of uniform dispersion and distribution, the issues like aggregation and agglomeration might sometimes arise. A modifying

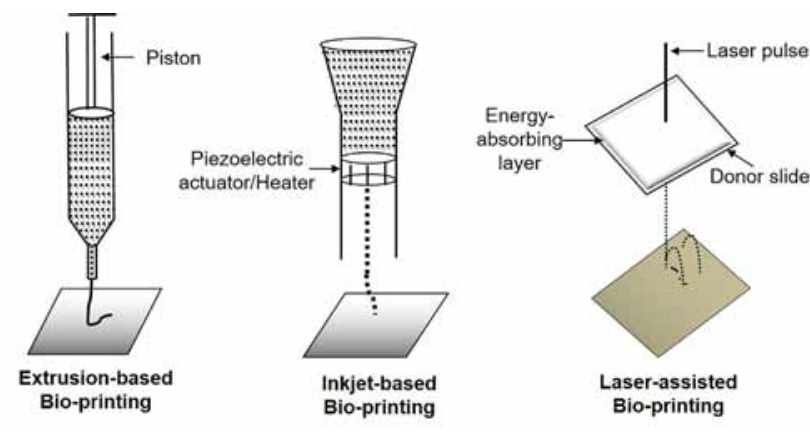

Figure 1: Extrusion based bioprinting, Inkjet based bioink, Laser assisted bioprinting. the process chemically is necessary for incorporating CNC into various polymer matrix systems efficiently. ${ }^{84}$ Thus, inventions in $3 \mathrm{D}$ printing linked to renewable nanoderivatives like CNC are expected to offer novel bioinks which are not harmful to the environment and human beings.

\section{Applications of Cellulosic Bioink}

Nano scaled version of cellulose viz. Cellulose nanofibre $(\mathrm{CNF})$ and cellulose nanocrystal $(\mathrm{CNC})$ is a novel biomaterial that can be produced from variety of renewable resources which are biodegradable and holds great potential in biomedical field, due to its remarkable chemical, mechanical and biocompatible properties. As a novel biomaterial, cellulose can be deposited in layers to form 3D to form 3D construct that has potentially diverse applications. Recently, 3D printing of cellulose based bioink or combination of cellulose with other biomaterials (Hybrid bioink) has gained attention of researchers. The nanocellulose due to their excellent shear-thinning behaviour and ability to support cell growth makes it more selective biomaterial in formulation of bioink. Thus, recent applications of current and prospective bioinks are described in the Table 3.

\begin{tabular}{|c|c|c|}
\hline \multicolumn{3}{|c|}{ Table 3: Cellulosic bioink for 3D printing. } \\
\hline $\begin{array}{c}\text { Biomaterial / Blend of } \\
\text { biomaterials }\end{array}$ & Applications & Reference \\
\hline $\begin{array}{c}\text { Cellulosic nanofibres and } \\
\text { alginate sulphate }\end{array}$ & Cartilage printing & 85 \\
\hline $\begin{array}{c}\text { Cellulose nanocrystals } \\
\text { and alginate }\end{array}$ & $\begin{array}{c}\text { liver-mimetic } \\
\text { construct }\end{array}$ & 16 \\
\hline $\begin{array}{c}\text { Nanocellulosic and } \\
\text { Hyluronic acid }\end{array}$ & $\begin{array}{c}\text { Encapsulation of } \\
\text { adipocytes }\end{array}$ & 86 \\
\hline $\begin{array}{c}\text { Nanocellulose/Alginate/ } \\
\text { glycerine composites }\end{array}$ & $\begin{array}{c}\text { Wound healing } \\
\text { applications. }\end{array}$ & 87 \\
\hline $\begin{array}{c}\text { Wood-based } \\
\text { bioactive glass modified } \\
\text { gelatin-alginate }\end{array}$ & $\begin{array}{c}\text { 3D bioprinting of } \\
\text { bone cells }\end{array}$ & 88 \\
\hline $\begin{array}{c}\text { Eudragit and ethyl } \\
\text { cellulose based bioink }\end{array}$ & $\begin{array}{c}\text { 3D bioprinted drug } \\
\text { loaded implants for } \\
\text { controlled release }\end{array}$ & \\
\hline $\begin{array}{c}\text { Cellulosic nanofibrils and } \\
\text { cross-linkable xylans }\end{array}$ & $\begin{array}{c}\text { Biomimetic inks for } \\
\text { 3D bioprinting }\end{array}$ & 15 \\
\hline $\begin{array}{c}\text { Cellulose-alginate based } \\
\text { bioink }\end{array}$ & $\begin{array}{c}\text { Bioprinting of human } \\
\text { chondrocytes }\end{array}$ & 90 \\
\hline $\begin{array}{c}\text { TEMPO oxidized and } \\
\text { Carboxymethylated } \\
\text { CNF along with calcium } \\
\text { chloride }\end{array}$ & $\begin{array}{c}\text { Wound healing } \\
\text { application }\end{array}$ & 91 \\
\hline $\begin{array}{c}\text { Methylcellulose-alginate } \\
\text { based bioink }\end{array}$ & $\begin{array}{c}\text { Tissue engineering } \\
\text { applications }\end{array}$ & 92 \\
\hline
\end{tabular}




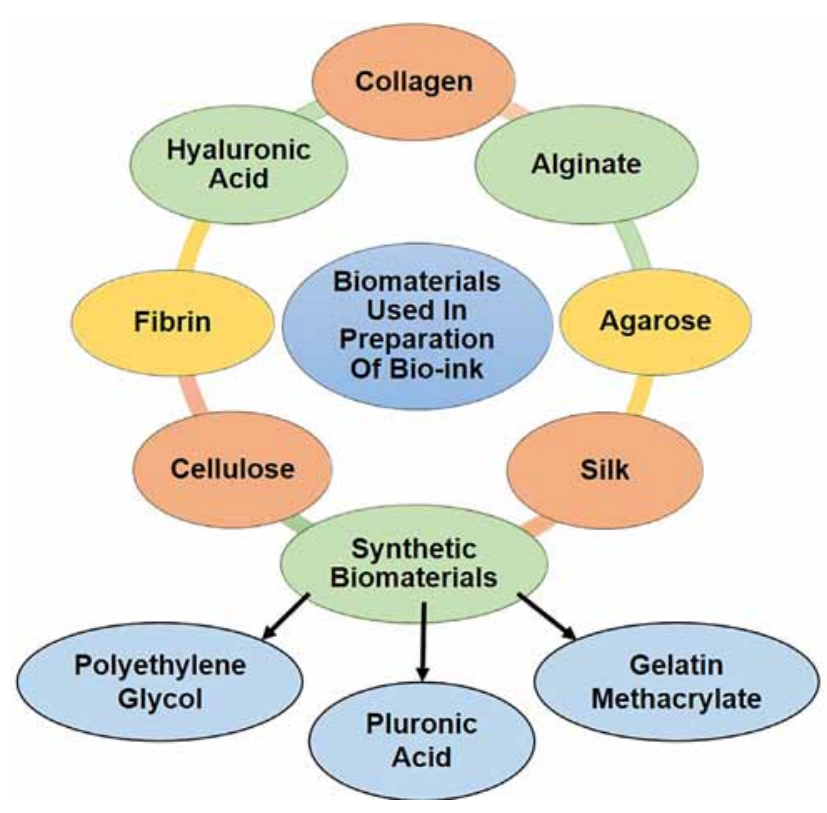

Figure 2: Biomaterials for bioink.
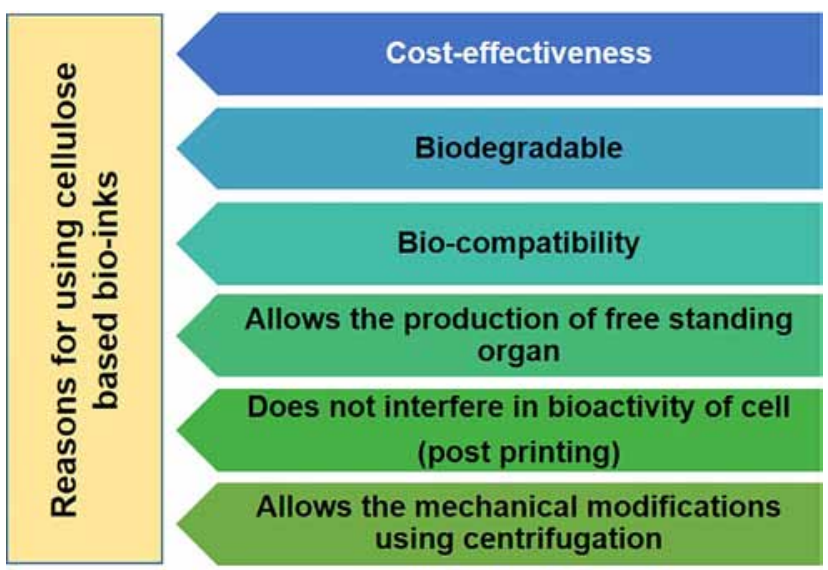

Figure 3: Reasons for using cellulose as a bioink.

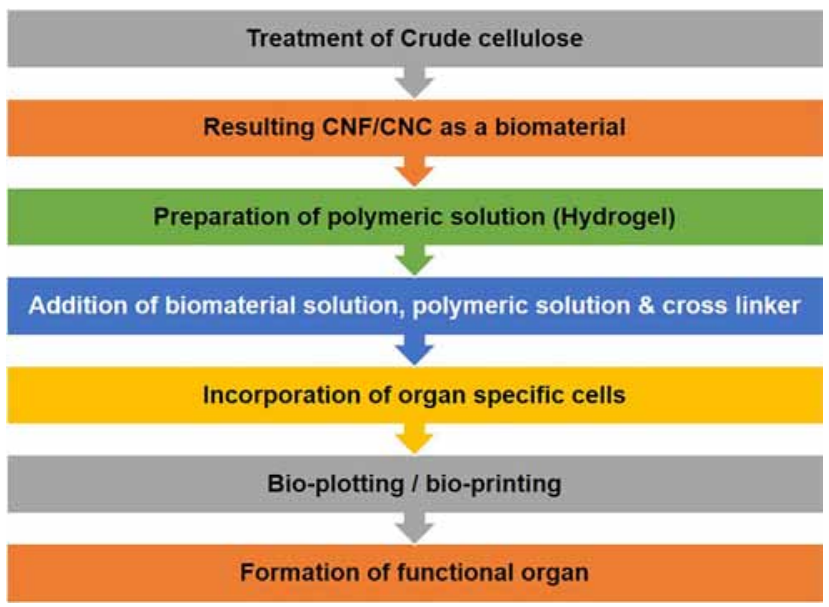

Figure 4: General procedure for preparation of cellulose bioink.

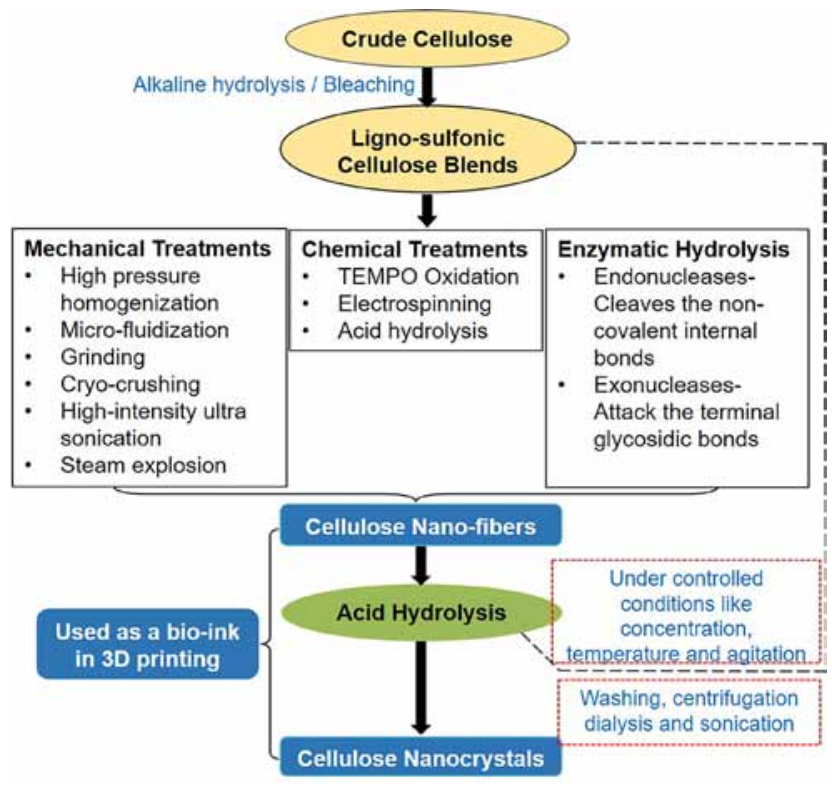

Figure 5: Pre-treatment of cellulose to obtain nanocellulose.

\section{CONCLUSION AND FUTURE PERSPECTIVE}

Cellulosic bioink has the robust capabilities of producing organ and tissues with ease using the $3 \mathrm{D}$ bioprinting technique. However, being a emerging research area with huge potential it needs further enhancements. The reviewed literature showed the advantages/applications of cellulosic bioink in this field. Cellulose being a natural, sustainable and biocompatible material with additional advantages like cost-effectiveness and easy availability has got numerous applications like biological applications, tissue engineering, regenerative medicines and wound healing. Cellulose in formulation of bioinks are used after treatments like TEMPO oxidation or combination of C-periodate either in nanofibrils or in nanocrystals form. The growth in manufacturing of ideal cellulosic bioink is still in progress. Due to aids of researchers all over the world, commercialization of cellulosic bioink is expected in near future. To our insight, the extensive exploration that has been done till now mainly emphasizes on different cellulosic composites in formulating bioink.

Even though, the properties of nanocellulose derivatives are acknowledged in biological applications. Amongst other properties, the most expedient characteristics of such derivatives to be considered into account is rheology. The rheological properties should be adjusted as per the requirements of $3 \mathrm{D}$ printing technology or depends on the type of organ/tissues to be printed. Rheology is significantly affected by origin of cellulose (procuring 
source), existence of impurities and characteristic feature of cellulosic fibers which is aspect ratio (Length of cellulosic nanofibrils: Width of cellulosic nanofibrils). Elementary changes in concentration of dry matter and consolidation of nanoparticles inside 3D network helps in altering mechanical properties of formulation. Alteration of properties by chemical functionalization of cellulosic derivative is also considered as an option.

Moreover, cellulosic derivatives can be used as viscosity alterants which helps in enhancing the rheological behaviour of other polymer, assuring required viscosity and non-newtonian behaviour. Due to this, when such materials are used all together or in combination with another polymer, it helps in formulating stable bioink. The new development of cellulosic bioink being a emerging research area in field of biomaterials holds the massive potential and shows advanced applications in regenerating organs/tissues using 3D bioprinting.

\section{ACKNOWLEDGEMENT}

Authors are thankful to Dr. D. Y. Patil Institute of Pharmaceutical Sciences and Research, Pimpri, Pune, MS, India for providing e-Library support for accessing the recent articles cited in the review papers.

\section{CONFLICT OF INTEREST}

The authors declare no conflict of interest.

\section{ABBREVIATIONS}

CNF: Cellulose nanofibre; CNC: Cellulose nanocrystal; ECM: Extra cellular matrix; HA: hyluronic acid; PEG: Polyethylene glycol; NA: Not applicable.

\section{REFERENCES}

1. Stansbury JW, Idacavage MJ. 3D printing with polymers: Challenges among expanding options and opportunities. Dental Materials. 2016;32(1):54-64.

2. Gopinathan J, Noh I. Recent trends in bioinks for 3D printing. Biomaterials Research. 2018;22(1):11.

3. Derby B. Printing and prototyping of tissues and scaffolds. Science. 2012;338(6109):921-6.

4. Kirchmajer DM, Gorkin IR. An overview of the suitability of hydrogel-forming polymers for extrusion-based 3D-printing. Journal of Materials Chemistry B. 2015;3(20):4105-17.

5. Forgacs G, Marga F, Jakab K. Applications of extrusion bioprinting Past, present, future. 3D Bioprinting in Regenerative Engineering: Principles and Applications. 2018.

6. Chameettachal S, Pati F. Inkjet-based 3D bioprinting. 3D Bioprinting in Regenerative Engineering: Principles and Applications. CRC. 2018;100-20.

7. Zimmermann R, Hentschel C, Schrön F, Moedder D, Büttner T, Atallah $\mathrm{P}$, et al. High resolution bioprinting of multi-component hydrogels. Biofabrication. 2019;11(4):045008.

8. Zheng Q, Lu J, Chen H, Huang L, Cai J, Xu Z. Application of inkjet printing technique for biological material delivery and antimicrobial assays. Analytical Biochemistry. 2011;410(2):171-6.
9. Guillotin B, Souquet A, Catros S, Duocastella M, Pippenger B, Bellance S, et al. Laser assisted bioprinting of engineered tissue with high cell density and microscale organization. Biomaterials. 2010;31(28):7250-6.

10. Devillard $R$, Pagès $E$, Correa $M M$, Kériquel $V$, Rémy $M$, Kalisky $J$, et al. Cell patterning by laser-assisted bioprinting. In Methods in Cell Biology. 2014;119:159-74. Academic Press.

11. Guillemot F, Guillotin B, Fontaine A, Ali M, Catros S, Kériquel V, et al. Laserassisted bioprinting to deal with tissue complexity in regenerative medicine. Mrs Bulletin. 2011;36(12):1015-9.

12. Stanton MM, Samitier J, Sanchez S. Bioprinting of 3D hydrogels. Lab on a Chip. 2015;15(15):3111-5.

13. He Y, Yang F, Zhao H, Gao Q, Xia B, Fu J. Research on the printability of hydrogels in 3D bioprinting. Scientific Reports. 2016;6:29977.

14. Joseph J, Deshmukh K, Tung T, Chidambaram K, Pasha SK. 3D Printing Technology of Polymer Composites and Hydrogels for Artificial Skin Tissue Implementations. In Polymer Nanocomposites in Biomedical Engineering: Springer, Cham. 2019;205-33.

15. Markstedt K, Escalante A, Toriz G, Gatenholm P. Biomimetic inks based on cellulose nanofibrils and cross-linkable xylans for 3D printing. ACS Applied Materials and Interfaces. 2017;9(46):40878-86

16. Yun Wu, Zhi YWL, Andrew CW, Kam CT, Xiaowu ST. 3D Bioprinting of Liver-mimetic Construct with Alginate/Cellulose Nanocrystal Hybrid Bioink. Bioprinting. 2018;9:1-6. https://doi.org/10.1016/j.bprint.2017.12.001

17. Leppiniemi J, Lahtinen P, Paajanen A, Mahlberg R, Metsä-Kortelainen S, Pinomaa T, et al. 3D-printable bioactivated nanocellulose-alginate hydrogels. ACS Applied Materials and Interfaces. 2017;9(26):21959-70.

18. Hospodiuk M, Dey M, Sosnoski D, Ozbolat IT. The bioink: A comprehensive review on bioprintable materials. Biotechnology Advances. 2017;35(2):21739.

19. Yin J, Zhao D, Liu J. Trends on physical understanding of bioink printability. Bio-Design and Manufacturing. 2019;2(1):50-4.

20. Hsu L, Jiang X. 'Living'Inks for 3D Bioprinting. Trends in Biotechnology. 2019;37(8):795-6.

21. Navarro J, Calderon GA, Miller JS, Fisher JP. Bioinks for Three-Dimensional Printing in Regenerative Medicine. In Principles of Regenerative Medicine. 2019;805-30. Academic Press.

22. Joung D, Truong V, Neitzke CC, Guo SZ, Walsh PJ, Monat JR, et al. 3D Printed Stem-Cell Derived Neural Progenitors Generate Spinal Cord Scaffolds. Advanced Functional Materials. 2018;28(39):1801850.

23. Chimene D, Lennox KK, Kaunas RR, Gaharwar AK. Advanced bioinks for 3D printing: a materials science perspective. Annals of Biomedical Engineering. 2016;44(6):2090-102.

24. Ning L, Zhu N, Mohabatpour F, Sarker MD, Schreyer DJ, Chen XB. Bioprinting Schwann cell-laden scaffolds from low-viscosity hydrogel compositions. Journal of Materials Chemistry B. 2019;7(29):4538-51.

25. Koosha F, Silverman D, Taboada S, Li J, Rafailovich M. Evaluation of Rheological Properties and Cytotoxicity of Bioinks. MRS Advances. 2019;4(22):1275-83

26. Groll J, Yoo JJ. Special issue on bioinks. Biofabrication. 2018;11(1):010201.

27. Liu W, Heinrich MA, Zhou Y, Akpek A, Hu N, Liu X, et al. Extrusion bioprinting of shear-thinning gelatin methacryloyl bioinks. Advanced Healthcare Materials. 2017;6(12):1601451.

28. Highley $C B$, Rodell $C B$, Burdick JA. Direct $3 D$ printing of shear-thinning hydrogels into self-healing hydrogels. Advanced Materials. 2015;27(34):50759.

29. Kabirian F, Mozafari M. Decellularized ECM-derived Bioinks: Prospects for the future. Methods. 2019.

30. Chameettachal S, Sasikumar S, Sethi S, Sriya Y, Pati F. Tissue/organ-derived bioink formulation for 3D bioprinting. Journal of 3D Printing in Medicine. 2019;3(1):39-54.

31. Malda J, Frondoza CG. Microcarriers in the engineering of cartilage and bone. Trends in Biotechnology. 2006;24(7):299-304.

32. Müller M, Becher J, Schnabelrauch M, Zenobi-Wong M. Nanostructured Pluronic hydrogels as bioinks for 3D bioprinting. Biofabrication. 2015;7(3):035006.

33. Wang $Y$, Huang $X$, Shen $Y$, Hang $R$, Zhang $X$, Wang $Y$, et al. Direct writing alginate bioink inside pre-polymers of hydrogels to create patterned vascular networks. Journal of Materials Science. 2019;54(10):7883-92. 
34. Ashammakhi N, Ahadian S, Pountos I, Hu SK, Tellisi N, Bandaru P, et al. In situ three-dimensional printing for reparative and regenerative therapy. Biomedical Microdevices. 2019;21(2):42.

35. Fedorovich NE, DeWijn JR, Verbout AJ, Alblas J, Dhert WJ. Threedimensional fiber deposition of cell-laden, viable, patterned constructs for bone tissue printing. Tissue Engineering Part A. 2008;14(1):127-33.

36. Ouyang L, Yao R, Zhao Y, Sun W. Effect of bioink properties on printability and cell viability for $3 \mathrm{D}$ bioplotting of embryonic stem cells. Biofabrication. 2016;8(3):035020.

37. Yu Y, Zhang Y, Martin JA, Ozbolat IT. Evaluation of cell viability and functionality in vessel-like bioprintable cell-laden tubular channels. Journal of Biomechanical Engineering. 2013;135(9):091011.

38. Ozbolat IT. Scaffold-based or scaffold-free bioprinting: Competing or complementing approaches?. Journal of Nanotechnology in Engineering and Medicine. 2015;6(2):024701.

39. Datta P, Barui A, Wu Y, Ozbolat V, Moncal KK, Ozbolat IT. Essential steps in bioprinting: From pre-to post-bioprinting. Biotechnology Advances. 2018;36(5):1481-504.

40. Zhang YS, Aleman J, Arneri A, Bersini S, Piraino F, Shin SR, et al. From cardiac tissue engineering to heart-on-a-chip: Beating challenges. Biomedical Materials. 2015;10(3):034006.

41. Choi YJ, Park JH, Jang J, Cho DW. 3D bioprinting technologies and bioinks for therapeutic and tissue engineering applications. Journal of 3D Printing in Medicine. 2018;2(4):187-203.

42. Zhang YS, Yue K, Aleman J, Mollazadeh-Moghaddam K, Bakht SM, Yang $\mathrm{J}$, et al. 3D bioprinting for tissue and organ fabrication. Annals of Biomedical Engineering. 2017;45(1):148-63.

43. Ozbolat IT, Yu Y. Bioprinting toward organ fabrication: Challenges and future trends. IEEE Transactions on Biomedical Engineering. 2013;60(3):691-9.

44. Zhu W, Ma X, Gou M, Mei D, Zhang K, Chen S. 3D printing of functional biomaterials for tissue engineering. Current Opinion in Biotechnology. 2016;40:103-12.

45. Ferreira AM, Gentile P, Chiono V, Ciardelli G. Collagen for bone tissue regeneration. Acta Biomaterialia. 2012;8(9):3191-200.

46. Yang X, Lu Z, Wu H, Li W, Zheng L, Zhao J. Collagen-alginate as bioink for three-dimensional (3D) cell printing based cartilage tissue engineering. Materials Science and Engineering: C. 2018;83:195-201.

47. Stratesteffen H, Köpf M, Kreimendahl F, Blaeser A, Jockenhoevel S, Fischer $\mathrm{H}$. GelMA-collagen blends enable drop-on-demand 3D printablility and promote angiogenesis. Biofabrication. 2017;9(4):045002.

48. Gudapati H, Dey M, Ozbolat I. A comprehensive review on droplet-based bioprinting: 6ast, present and future. Biomaterials. 2016;102:20-42.

49. Zhang Y, Yu Y, Chen H, Ozbolat IT. Characterization of printable cellular microfluidic channels for tissue engineering. Biofabrication. 2013;5(2):025004.

50. Gao Q, He Y, Fu JZ, Liu A, Ma L. Coaxial nozzle-assisted 3D bioprinting with built-in microchannels for nutrients delivery. Biomaterials. 2015;61:203-15.

51. Fedorovich NE, DeWijn JR, Verbout AJ, Alblas J, Dhert WJ. Threedimensional fiber deposition of cell-laden, viable, patterned constructs for bone tissue printing. Tissue Engineering Part A. 2008;14(1):127-33.

52. Kreimendahl F, Köpf M, Thiebes AL, Duarte CDF, Blaeser A, Schmitz-Rode $\mathrm{T}$, et al. Three-dimensional printing and angiogenesis: Tailored agarose-type I collagen blends comprise three-dimensional printability and angiogenesis potential for tissue-engineered substitutes. Tissue Engineering Part C: Methods. 2017;23(10):604-15.

53. Gu Q, Tomaskovic-Crook E, Lozano R, Chen Y, Kapsa RM, Zhou Q, et al. Functional 3D neural mini-tissues from printed gel-based bioink and human neural stem cells. Advanced Healthcare Materials. 2016;5(12):1429-38.

54. Floren M, Bonani W, Dharmarajan A, Motta A, Migliaresi C, Tan W. Human mesenchymal stem cells cultured on silk hydrogels with variable stiffness and growth factor differentiate into mature smooth muscle cell phenotype. Acta Biomaterialia. 2016;31:156-66.

55. Das S, Pati F, Choi YJ, Rijal G, Shim JH, Kim SW, et al. Bioprintable, cellladen silk fibroin-gelatin hydrogel supporting multilineage differentiation of stem cells for fabrication of three-dimensional tissue constructs. Acta Biomaterialia. 2015;11:233-46.

56. Zheng Z, Wu J, Liu M, Wang H, Li C, Rodriguez MJ, et al. 3D Bioprinting of Self-Standing Silk-Based Bioink. Advanced Healthcare Materials. 2018;7(6):1701026.
57. Cui $X$, Boland T. Human microvasculature fabrication using thermal inkjet printing technology. Biomaterials. 2009;30(31):6221-7.

58. England S, Rajaram A, Schreyer DJ, Chen X. Bioprinted fibrin-factor XIIIhyaluronate hydrogel scaffolds with encapsulated Schwann cells and their in vitro characterization for use in nerve regeneration. Bioprinting. 2017;5:1-9.

59. Zhang K, Fu Q, Yoo J, Chen X, Chandra P, Mo X, et al. 3D bioprinting of urethra with PCL/PLCL blend and dual autologous cells in fibrin hydrogel: An in vitro evaluation of biomimetic mechanical property and cell growth environment. Acta Biomaterialia. 2017;50:154-64.

60. Yoo HS, Lee EA, Yoon JJ, Park TG. Hyaluronic acid modified biodegradable scaffolds for cartilage tissue engineering. Biomaterials. 2005;26(14):1925-33.

61. Poldervaart MT, Goversen B, DeRuijter M, Abbadessa A, Melchels FP, Öner FC, et al. 3D bioprinting of methacrylated hyaluronic acid (MeHA) hydrogel with intrinsic osteogenicity. PloS One. 2017;12(6):e0177628.

62. Sakai S, Ohi H, Hotta T, Kamei H, Taya M. Differentiation potential of human adipose stem cells bioprinted with hyaluronic acid/gelatin-based bioink through microextrusion and visible light-initiated crosslinking. Biopolymers. 2018;109(2):e23080.

63. Burdick JA, Prestwich GD. Hyaluronic acid hydrogels for biomedical applications. Advanced Materials. 2011;23(12):H41-56.

64. Wu W, DeConinck A, Lewis JA. Omnidirectional printing of 3D microvascular networks. Advanced Materials. 2011;23(24):H178-83.

65. Mozetic P, Giannitelli SM, Gori M, Trombetta M, Rainer A. Engineering muscle cell alignment through $3 \mathrm{D}$ bioprinting. Journal of Biomedical Materials Research Part A. 2017;105(9):2582-8.

66. Müller M, Becher J, Schnabelrauch M, Zenobi-Wong M. Nanostructured Pluronic hydrogels as bioinks for $3 D$ bioprinting. Biofabrication. 2015;7(3):035006.

67. Gaharwar AK, Peppas NA, Khademhosseini A. Nanocomposite hydrogels for biomedical applications. Biotechnology and Bioengineering. 2014;111(3):44153.

68. Kobayashi K, Huang $\mathrm{Cl}$, Lodge TP. Thermoreversible gelation of aqueous methylcellulose solutions. Macromolecules. 1999;32(21):7070-7.

69. Markstedt K, Escalante A, Toriz G, Gatenholm P. Biomimetic inks based on cellulose nanofibrils and cross-linkable xylans for 3D printing. ACS Applied Materials and Interfaces. 2017;9(46):40878-86.

70. Ávila HM, Schwarz S, Rotter N, Gatenholm P. 3D bioprinting of human chondrocyte-laden nanocellulose hydrogels for patient-specific auricular cartilage regeneration. Bioprinting. 2016;1:22-35.

71. Sultan S, Mathew A. 3D printed porous bioscaffolds based on cellulose nanocrystals. In 3D Printing Technology and Innovations-March 25-26, 2019 Rome, Italy. 2019.

72. Wang Q, Sun J, Yao Q, Ji C, Liu J, Zhu Q. 3D printing with cellulose materials. Cellulose. 2018;25(8):4275-301.

73. Sultan S, Siqueira G, Zimmermann T, Mathew AP. 3D printing of nanocellulosic biomaterials for medical applications. Current Opinion in Biomedical Engineering. 2017;2:29-34.

74. Compton BG, Lewis JA. 3D-printing of lightweight cellular composites Advanced Materials. 2014;26(34):5930-5.

75. Hubbe MA, Rojas OJ, Lucia LA, Sain M. Cellulosic nanocomposites: A review. Bio Resources. 2008;3(3):929-80.

76. Siró I, Plackett D. Microfibrillated cellulose and new nanocomposite materials A review. Cellulose. 2010;17(3):459-94.

77. Gindl W, Keckes J. All-cellulose nanocomposite. Polymer. 2005;46(23):102215.

78. Habibi Y, Lucia LA, Rojas OJ. Cellulose nanocrystals: Chemistry, selfassembly and applications. Chemical Reviews. 2010;110(6):3479-500.

79. Bondeson D, Mathew A, Oksman K. Optimization of the isolation of nanocrystals from microcrystalline cellulose by acid hydrolysis. Cellulose. 2006;13(2):171.

80. Lu P, Hsieh YL. Preparation and properties of cellulose nanocrystals: Rods, spheres and network. Carbohydrate Polymers. 2010;82(2):329-36.

81. Siqueira G, Kokkinis D, Libanori R, Hausmann MK, Gladman AS, Neels A, et al. Cellulose nanocrystal inks for 3D printing of textured cellular architectures. Advanced Functional Materials. 2017;27(12):1604619.

82. Wang J, Chiappone A, Roppolo I, Shao F, Fantino E, Lorusso M, Rentsch $D$, et al. All-in-One Cellulose Nanocrystals for 3D Printing of Nanocomposite Hydrogels. Angewandte Chemie International Edition. 2018;57(9):2353-6. 
Palaganas NB, Mangadlao JD, DeLeon AC, Palaganas JO, Pangilinan KD, Lee $\mathrm{YJ}$, et al. 3D printing of photocurable cellulose nanocrystal composite for fabrication of complex architectures via stereolithography. ACS Applied Materials and Interfaces. 2017;9(39):34314-24.

84. Du H, Liu W, Zhang M, Si C, Zhang X, Li B. Cellulose nanocrystals and cellulose nanofibrils based hydrogels for biomedical applications. Carbohydrate Polymers. 2019;209:130-44.

85. DeMoriA, Peña FM, Blunn G, Tozzi G, Roldo M. 3D printing and electrospinning of composite hydrogels for cartilage and bone tissue engineering. Polymers. 2018;10(3):285.

86. Henriksson I, Gatenholm P, Hägg DA. Increased lipid accumulation and adipogenic gene expression of adipocytes in 3D bioprinted nanocellulose scaffolds. Biofabrication. 2017;9(1):015022.

87. Gumrah DA. Nanocellulose and its composites for biomedical applications. Current Medicinal Chemistry. 2017;24(5):512-28.
88. Ojansivu M, Rashad A, Ahlinder AE, Massera J, Mishra A, Syverud K, et al. Wood-based nanocellulose and bioactive glass modified gelatin-alginate bioinks for 3D bioprinting of bone cells. Biofabrication. 2019;11(3):035010.

89. Moulton SE, Wallace GG. 3-dimensional (3D) fabricated polymer based drug delivery systems. Journal of Controlled Release. 2014;193:27-34.

90. Markstedt K, Mantas A, Tournier I, Martínez ÁH, Hägg D, Gatenholm P. 3D bioprinting human chondrocytes with nanocellulose-alginate bioink for cartilage tissue engineering applications. Biomacromolecules. 2015;16(5):1489-96.

91. Rees A, Powell LC, Chinga-Carrasco G, Gethin DT, Syverud K, Hill KE, et al. 3D bioprinting of carboxymethylated-periodate oxidized nanocellulose constructs for wound dressing applications. Bio Med Research International. 2015.

92. Liu J, Sun L, Xu W, Wang Q, Yu S, Sun J. Current advances and future perspectives of $3 \mathrm{D}$ printing natural-derived biopolymers. Carbohydrate Polymers. 2018.

\section{PICTORIAL ABSTRACT}

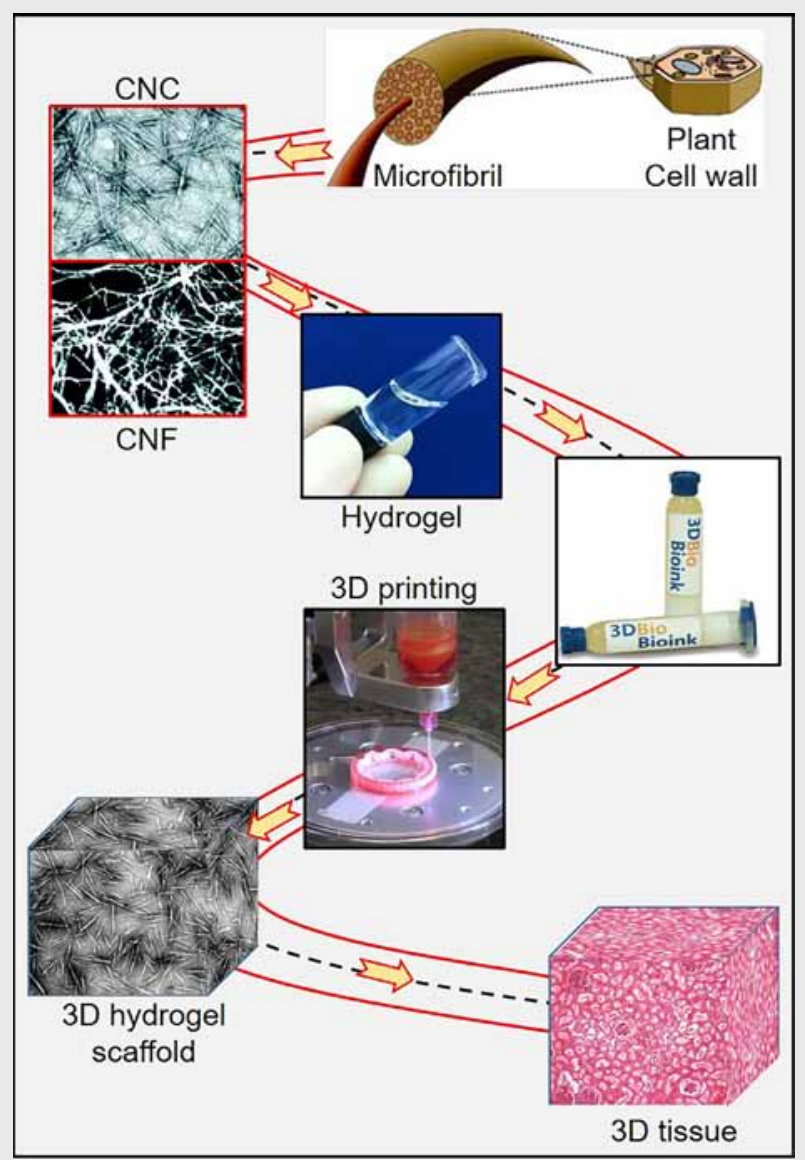

\section{SUMMARY}

Bioinks are one of the key element in the in 3D printing (additive manufacturing) technique which is being very exhaustively studied for tissue engineering and regenerative medicine applications. One of the essential characteristic of the bioink is shear thinning property. The incorporation of cellulose nanocrystals (CNC) and cellulose nano-fibers (CNF) in different natural and synthetic hydrogels provide excellent shear thinning property and also improves precision printing, water retention and sustain release capacity (drugs and growth factors) of the hydrogels. The current review provides brief procedure for the synthesis of $\mathrm{CNC}$ and $\mathrm{CNF}$, advantages and disadvantages of different bio-printing techniques and recent advances in cellulose based bioinks developed for different tissue engineering application. 


\section{About Authors}

Dr. Ravindra V. Badhe is currently working as Associate Professor, Pharmaceutical Chemistry Department at Dr. D. Y. Patil Institute of Pharmaceutical Sciences and Research, Pimpri, Pune, MS, India. He is having 3 years of Postdoctoral Experience from University of Witwatersrand, Johannesburg, RSA and University of Illinois at Chicago, Rockford, Illinois, USA in the field of Biomaterials, Microfluidic bioreactors, Regenerative medicine and novel drug delivery systems. He did his $\mathrm{PhD}$, Masters and Bachelors degree education in Pharmaceutical Sciences form Savitribai Phule Pune University (SPPU), Pune, MS, India. His expertise and core research areas are hydrogel based biomaterials, 3D scaffolds, Bioreactor development, wound healing, microfluidic and medical device development and novel drug delivery systems. He is currently working on 3D bone scaffolds, bone bio-inks, electro-conducting bio-inks, microfluidic device based toxicity, 4D bioreactors and advanced diagnostic medical device development.

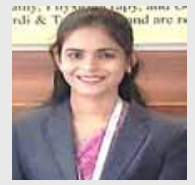

Ms. Anagha K. Godse is currently working as Assistant Professor, Pharmaceutical Chemistry Department at Dr. D. Y. Patil Institute of Pharmaceutical Sciences and Research, Pimpri, Pune, India. She is 2019 registered Ph.D students of the same institute. She did her dissertation work on electro-conducting bio-ink for wound healing. She did her masters and bachelors degree education in pharmaceutical science from Savitribai Phule Pune University (SPPU), Pune, MS, India. She is currently working on synthetic polymers and herbal dermatological formulations.

Cite this article: Badhe RV, Godse A, Ahinkar A. Biomaterials in 3D Printing: A Special Emphasis on Nanocellulose. Indian J of Pharmaceutical Education and Research. 2020;54(3):526-40. 